\title{
Sobre o escritor de sucesso e temas afins: conversa com Jorge Amado e Paulo Coelho
}

\author{
About success writer and related themes: \\ conversation with Jorge Amado and Paulo Coelho
}

\author{
SAYONARA AMARAL DE OLIVEIRA
}

Universidade do Estado da Bahia. Salvador, BA, Brasil. D

Resumo: Neste artigo, busca-se traçar um diálogo entre Jorge Amado e Paulo Coelho, a partir da representatividade cultural dos dois escritores. Discute-se o modo pelo qual a postura assumida por ambos junto ao mercado e à cultura midiática propicia uma dessublimação do ideal moderno de autonomia da arte, em sintonia com as transformações do campo literário nos tempos contemporâneos. Considerando que Coelho e Amado construíram trajetórias e produções literárias bastante distintas, o artigo pretende apresentar linhas de afinidade, numa perspectiva cultural, com vistas a compreender o que faz esses escritores serem reconhecidos, cada um ao seu modo, como "fenômenos" de público inigualáveis no Brasil.

Palavras-chave: Jorge Amado; Paulo Coelho; Campo literário; Mercado editorial; Cultura midiática.

\begin{abstract}
This article aims to build a dialogue between Jorge Amado and Paulo Coelho based on the cultural representativeness of the both of the writers. This paper discuss the way in which they assumed a special posture in the mediatic market and culture that provides a desublimation of the modern ideal of art's autonomy, It synchronizes with the transformations in the literary field in contemporaneity. This research considers that Coelho and Amado have built quite distinct trajectories and literary productions. This article intends to present lines of affinity between them through a cultural perspective, aims to understanding what makes these writers to be recognized as "phenomenon" to the unequaled public in the Brazil.
\end{abstract}

Keywords: Jorge Amado; Paulo Coelho; Literary field; Publishing market; Midiatic culture.

Ao contrário do que se constata acerca do intenso relacionamento que Jorge Amado travou com vários artistas e intelectuais brasileiros e estrangeiros, conforme atestado pelo vultoso número de cartas arquivadas na Fundação Casa de Jorge Amado, quase não há registros sobre as ligações que o eminente autor baiano tenha mantido com o não menos famoso escritor Paulo Coelho. Um desses registros, porém, mostra-se bastante profícuo para introduzir um diálogo entre os dois, contemplando afinidades e até mesmo uma insuspeitada aliança. Trata-se do texto publicado no jornal Diário do Nordeste, em 2015, intitulado "Ao maior de todos", no qual Paulo Coelho, tecendo uma homenagem a Jorge Amado, destaca momentos significativos em que seus caminhos se cruzaram, conforme transcrito a seguir:

Eu tinha editado, com meus próprios recursos, um livro chamado "Os Arquivos do Inferno". Todos nós sabemos o quanto é difícil publicar um trabalho, mas existe algo ainda mais complicado: fazer com que ele seja colocado nas livrarias.

Todas as semanas minha mulher ia visitar os livreiros em um lado da cidade, e eu ia para outra região fazer a mesma coisa. Foi assim que, com exemplares de meu livro debaixo do braço, ela ia atravessando a Avenida Copacabana, e eis que Jorge Amado e Zélia Gattai estão do outro lado da calçada! Sem pensar muito, ela os abordou e disse que o marido era escritor. Jorge e Zélia (que provavelmente deviam escutar isso todos os dias) a trataram com o maior carinho, convidaram para um café, pediram um exemplar, e terminaram desejando que tudo corresse bem com minha carreira literária.

"Você é louca!", eu disse, quando ela voltou para casa. "Não vê que ele é o mais importante escritor brasileiro?

$[\ldots]$ 
Recebo finalmente meu primeiro prêmio literário no exterior - mais precisamente, na França. Acontece que, no dia da entrega, estarei em Los Angeles por causa de compromissos assumidos anteriormente. Anne Carriére, minha editora, fica desesperada. [...] A data do prêmio chegando, e o premiado não poderá ir; o que fazer? Anne, sem me consultar, liga para Jorge Amado e explica a situação. Na mesma hora, Jorge se oferece para me representar na entrega do prêmio. E não se limita a isso: telefona para o embaixador brasileiro e o convida, faz um lindo discurso, deixa todos os presentes emocionados. O mais curioso de tudo isto, é que eu só iria conhecer Jorge Amado pessoalmente quase um ano depois da entrega do prêmio. Mas sua alma, ah, essa eu aprendera a admirar como eu admiro seus livros: um escritor famoso que jamais despreza os principiantes, um brasileiro que fica contente com o sucesso de seus conterrâneos, um ser humano sempre pronto a ajudar quando lhe pedem algo (COELHO, 2015).

No texto, embora não sejam mencionadas datas, nota-se que os dois episódios narrados estão dispostos em uma cronologia, permitindo divisar o trajeto de uma aproximação que se inicia timidamente, no início dos anos 1980, com o desconhecimento total que Jorge Amado, detentor de uma carreira literária consolidada, manifesta em relação ao escritor iniciante. E este último mostra-se inibido, tal como ficaria um fã diante do ídolo. O segundo episódio, ocorrido anos depois, tem sabor de grand finale, pois o lustre escritor irá não somente reconhecer bem como aprovar o êxito do jovem autor seu conterrâneo, o qual se tornara também, àquela altura, um grande sucesso literário no mercado internacional. A aprovação de Amado se confirma quando toma a iniciativa de representar pessoalmente Paulo Coelho na cerimônia de premiação na França, fato que ocorreu em 1995, na entrega do Grande Prêmio Literário das Leitoras da Revista Elle, conforme foi amplamente noticiado pelos jornais da época.

Receber o prêmio conferido a um outro, em nome deste outro, é o mesmo que depositar sobre ele o seu crédito e, quiçá, selar um pacto de cumplicidade. Com a repercussão desse evento na mídia, tal manifestação de simpatia será rapidamente endossada numa entrevista que Jorge Amado concede, no calor da hora, para o jornal Folha de São Paulo. Em seu depoimento, ele deixa explícita a admiração pelo fato da premiação de Paulo Coelho ter sido conferida por leitoras e não por um grupo seleto de literatos, como de costume nos rituais de consagração do campo literário. Nos seus termos, "infeliz é aquele escritor que escreve para ganhar prêmios", pois, "o grande prêmio do escritor é o leitor". Em continuidade, afirma que o êxito internacional do autor de O Alquimista merece grande respeito e consideração, pois repercute sobre os demais escritores brasileiros, abrindo caminhos para a literatura nacional no exterior. "Todos nos beneficiamos", Jorge Amado conclui. E quando foi indagado sobre a possibilidade de Paulo Coelho passar a ser reconhecido pela crítica literária nacional graças à notoriedade que alcançara na França àquela ocasião, ele responde contundente:

Tom Jobim costumava dizer que o sucesso, no Brasil, é um insulto pessoal. Tem muita gente que fica contente com o sucesso do Paulo Coelho, mas a nossa vida literária tem muita coisa atrasada. Não há o respeito que há na Europa. Se há um escritor de sucesso aqui [na Europa], as pessoas não saem negando. No Brasil, negam. José Mauro de Vasconcelos era um romancista muito bem-visto, elogiado. De repente, ele teve um livro que teve um sucesso imenso - "O Meu Pé de Laranja-Lima" - no Brasil e fora do Brasil. Aí ele foi atacadíssimo. Negaram pão e água a ele. Não sei se o sucesso de Paulo Coelho vai levar a um aplauso da chamada elite intelectual brasileira. Duvido. Enfim, desejo que sim (AMADO, 1995).

No aval que concede ao sucesso de Paulo Coelho, seguindo na contramão do que opinaria uma "elite intelectual", vislumbra-se a defesa que Amado poderia fazer de si mesmo, tendo em vista que, muito antes do exparceiro de Raul Seixas ingressar no mercado editorial, ele próprio foi também duramente atacado pela crítica, em função do êxito massivo alcançado por sua obra. Em Navegação de Cabotagem, o seu livro de memórias, Jorge Amado não passa ao largo desta questão, quando evoca o seguinte trecho de uma conversa que tivera com Érico Veríssimo: "Certos críticos, quase sempre os mesmos, alguns sérios e amargos, outros brilhantes e salafrários, nunca nos perdoaram o público que nossos livros conquistaram, nos malharam a vida inteira" (AMADO, 2006, p. 621).

$\mathrm{Na}$ história do campo literário, a recusa da crítica especializada diante de um escritor que conquista vastos públicos está para muito além do sentimento de inveja ou despeito, como faria supor uma visão do senso comum acerca das relações conflituosas entre críticos e produtores de arte. Grosso modo, aquela recusa tem como lastro o ensejo de demarcar um território simbólico que se quer autônomo e distinto para o mundo da arte, imune às interferências externas, sobretudo às do poder econômico, que culminariam por descaracterizar os preceitos e valores defendidos pelo campo. Entre esses valores, destaca-se a autossuficiência do código estético e o alto prestígio conferido à figura do escritor, o qual, em nome dessa autossuficiência, não se subordinaria às sanções comerciais, representativas da abertura do campo a um mercado consumidor constituído pela "massa" de leitores anônimos, não especializados e, portanto, alheios às exigências da estética culta. 
Trata-se, portanto e ainda, da antiga distinção, firmada no seio da chamada alta modernidade, entre um campo de produção erudita, onde impera o valor de raridade e o domínio de um código estético dito superior, e o campo das industrias culturais, com seus mecanismos massificadores de divulgação e consumo. De acordo com os estudos de Pierre Bourdieu (1996), é a partir dessa distinção - hoje bastante enfraquecida, cumpre lembrar -, que se consagra em fins do século XIX a figura aurática do artista ou intelectual moderno, cuja feição singular decorre da pretensa irredutibilidade da obra de arte ao estatuto de mercadoria e da crença na manutenção de uma esfera exclusiva para as artes. São conhecidas as inquietações envolvendo a relação artemercado nos posicionamentos de eminentes escritores modernos, como Gustave Flaubert, que chegou a declarar: "Sustento que uma obra de arte digna desse nome e feita com consciência é inapreciável, não tem valor comercial, não pode ser paga" (BOURDIEU, 1996, p. 101).

Embora o interesse de preservar um capital simbólico específico e distinto para a literatura ainda permaneça influente em alguns segmentos do campo, a exemplo de parcela da crítica especializada, observa-se que, na atualidade, tal concepção moderna de autonomia estética e cultural fica diminuída diante das novas determinações que as artes sofrem em um mercado em rápida expansão. Segundo Nestor Garcia Canclini (2003), com a dinâmica socioeconômica do desenvolvimento artístico que atravessou todo o século XX chegando à contemporaneidade, os interesses e investimentos na esfera artística se distendem e ganham novos contornos, articulados no intuito de atender ao mercado amplo de consumidores.

Mostram-se cada vez mais fluidas as fronteiras entre arte e mercado, assim como se observa uma reorganização no funcionamento dos campos artísticos e nos padrões de consagração tradicionalmente estruturados, o que se reflete sobremaneira na postura assumida pelos artistas ou produtores. Para ilustrar o modo pelo qual essas transformações afetam de forma decisiva os pressupostos da cultura moderna em matéria de arte, Canclini (2003, p. 63) tece o seguinte comentário: "É possível perguntar o que fariam hoje, dentro desse sistema, Leonardo, Mozart ou Baudelaire. A resposta é a que um crítico deu: 'Nada, a menos que eles jogassem conforme as regras". Ao que se poderia acrescentar: tal como bem o fizeram Jorge Amado e Paulo Coelho, à medida que se consagraram, cada um ao seu modo, "fenômenos" de público inigualáveis no Brasil.

Considerando que mais de cinquenta anos separam os marcos iniciais de suas respectivas carreiras de sucesso - O país do carnaval, em 1931, e $O$ diário de um mago, em 1987, é evidente que Amado e Coelho empreenderam trajetórias muito distintas. A diferença mais decisiva entre os dois, possivelmente, diz respeito aos seus projetos literários, e é o próprio Jorge Amado que cuida de demarcar essa distinção, numa entrevista concedida ao Jornal do Brasil, em 1992. Quando indagado acerca dos 2 milhões de exemplares de livros que Paulo Coelho já teria distribuído até aquela ocasião, Amado responde: "Acho estes números excelentes. Mas infelizmente não li nenhum destes livros, devo confessar minha ignorância. É culpa minha. Paulo Coelho não tem culpa disso. Acho bom que se vendam muitos livros, seja esotérico ou não. Sou materialista, não sou esotérico (AMADO, 1992, p. 2)."

Ao se autodeclarar um escritor materialista, evocando o legado do pensamento marxista que acompanhou a sua formação intelectual e política, Jorge Amado parece aludir ao fato de que sempre defendeu o lastro do real histórico em suas narrativas, preenchendo-as com personagens, cenas e situações que dizem da sociedade e da cultura brasileiras, as quais são representadas, grosso modo, tanto pelas mazelas sociais quanto pelo riso franco que irrompe das camadas populares e aponta para um horizonte de esperanças. O apego ao real "conduz a uma literatura voltada para o coletivo e seduzida pelo desejo de viver, interpretar e, até mesmo, 'fazer' a História", como observa Eduardo de Assis Duarte (1994, p.158), ao tratar da produção amadiana. Tal tendência, que envolve o projeto literário de Jorge Amado mesmo após a fase da escrita de orientação político-militante dos primórdios da carreira, o situa como um escritor engajado, comprometido com a iniciativa de pensar o país, seguindo uma tradição de intelectuais brasileiros, muitos dos quais compuseram com ele a chamada geração do romance de 30 .

Em direção oposta, a produção de Paulo Coelho, como a de outros escritores seus contemporâneos, já não se ocupa dos temas sociais clássicos ou das representações coletivas de um povo ou nação, investindo, antes, nas tramas vividas pelo sujeito individual, com fortes traços autobiográficos. E a obra de Coelho se distingue ainda mais por investir sistematicamente em experiências de transformação interior, levando as suas personagens à transcendência no plano da espiritualidade, pelas vias do simbolismo místico. A sua produção articula um imaginário esotérico new age, egresso da contracultura dos anos 1960-70, que o acompanha desde as letras das canções feitas em parceria com Raul Seixas e se dissemina, com maior ou menor intensidade, ao longo dos livros que vem publicando. Envolvidas por esse imaginário, as suas narrativas se apresentam predominantemente abstraídas de referências ao local ou nacional, temas caros à literatura brasileira de diferentes épocas, o que visivelmente o afasta daquela linhagem de escritores engajados, da qual Jorge Amado se fez notório representante.

Se no tocante ao exame da produção literária, a distância entre os dois escritores se mostra acentuada, 
o mesmo já não pode ser dito quando se parte para a dimensão institucional da literatura - a literatura entendida como um fato cultural ampliado, no qual se incluem as demandas, investimentos e trocas simbólicas inscritas no tecido social. Adotando essa perspectiva extraliterária, com enfoque na conduta profissional de um escritor, é que se pode observar o quanto os dois autores estão aproximados, por não comungarem daquela representação mitificada do artista moderno, segundo a qual a aliança entre arte e mercado constituiria alguma forma de demérito ou, no mínimo, um motivo de desconforto. A esse propósito, tome-se como ponto de partida o seguinte depoimento de Paulo Coelho:

Outro dia li uma entrevista de um escritor brasileiro, que diz estar contente por ser funcionário público e, assim, não precisar se 'submeter' às pressões do editor. Do que ele estava falando? Ou é de um mundo que eu não conheço ou talvez esteja justificando o seu próprio fracasso pessoal (COELHO, 2002, p. 13).

O "mundo que não conheço", referido em sua fala, remonta ao universo em que se fez vigorar uma moderna tradição literária no Brasil, nas primeiras décadas do século $\mathrm{XX}$, quando o campo artístico nacional contava com uma industrialização restringida e uma máquina cultural ainda incipiente, conforme assinala Renato Ortiz (2001). Nesse contexto, a impossibilidade do crescimento generalizado afetava o mercado de bens simbólicos, assim como a baixa escolarização e o elevado índice de analfabetismo da população constituíam fatores concorrentes para dificultar a formação de um público de leitores. Extensivamente, da parte dos artistas ou produtores, constata-se que "o escritor não podia 'viver da literatura', o que o levava a exercer funções no magistério e nos cargos públicos. É conhecido o fato de que, no Brasil, o desenvolvimento da literatura se encontra estreitamente ligado à burocracia do Estado" (ORTIZ, 2001, p. 28).

De acordo com o poeta e ensaísta José Paulo Paes (1990), a dificuldade de profissionalização do escritor engendrou o cultivo de uma tradição bacharelesca no país, cujos interesses se voltavam para a eleição de uma produção literária culta e a consequente obtenção do prestígio artístico junto ao campo restrito da cultura erudita: o círculo de confrades, dos resenhistas de livros, dos professores de literatura e de um pequeno contingente de leitores mais ou menos espontâneos. Paes (1990, p. 37) observa que "as condições brasileiras são propícias mais ao surgimento de literatos que de artesãos". Enquanto estes últimos assumem o estatuto de profissionais do mercado, atendendo largas parcelas de público, aqueles primeiros, ao declinarem dessa função, acabam por afastar o vasto segmento de potenciais leitores que eles ajudariam a conquistar e a constituir.
No decorrer de sua extensa trajetória profissional, Jorge Amado se afasta categoricamente dessa cultura de literatos, para a qual o reconhecimento artístico-cultural prescindiria da aceitação de públicos amplos. Não é por acaso que, naqueles primórdios do século $\mathrm{XX}$, enquanto uma parcela expressiva de artistas e intelectuais prestava serviços públicos, mantendo a atividade literária como prática subsidiária e desfrutando de posições que pareciam indiferentes às exigências do mercado, Amado foi um dos poucos escritores que se consagraram em tempo integral à produção de obras literárias e artísticas, de acordo com Sergio Micelli (2001).

Além de romancista, Jorge Amado exerceu as funções de jornalista, editor e escritor de roteiros e cenários de filmes e peças teatrais. Vale ressaltar que, durante o período em que seus livros foram censurados pela ditadura do Estado Novo, nos anos 1930, o autor escreveu, sob encomenda, um catálogo para a linha de cosméticos Coty, intitulado $A$ arte de ser bela, e também criou roteiros para chanchadas, o que the assegurou algum retorno financeiro (RIOS, 2006). Essas múltiplas atividades e incursões por instâncias culturais diversas confirmam a experiência e o know how adquiridos por um escritor que soube lidar de perto com o crescimento do mercado de bens simbólicos no Brasil, ao longo de uma carreira de mais de setenta anos.

Amado ingressou no campo literário em 1929, com a publicação em jornal do folhetim intitulado El-Rey, o qual foi posteriormente editado em livro, em 1930, recebendo o título de Lenita. Desde então, diante do percurso das publicações de seus romances em continuadas edições, reedições e traduções para outros idiomas, é notável que a sua obra também tenha sido vertida para o cordel, novelas de rádio, fotonovelas, histórias em quadrinhos e espetáculos de dança, alcançando uma popularidade excepcional sobretudo com as adaptações feitas para o cinema e a televisão.

Em seu estudo da recepção de Jorge Amado, Márcia Rios da Silva (2006:82) observa que esses registros são reveladores do modo pelo qual o escritor "habilmente criou estratégias de aproximação com o público, com seus fãs e leitores, para além das amarras impostas pela cultura letrada." De acordo com a pesquisadora, seja durante o período em que vivenciou a experiência de intelectual militante no Partido Comunista, seja passada esta fase, Amado cuidou de esvaziar a literatura de seu estatuto elitista. E tal posicionamento vem se deflagrar sobretudo com a presença maciça de sua obra na televisão, a partir dos anos 1970, momento em que essa mídia se torna hegemônica no território nacional e seus produtores recorrem à transposição das narrativas amadianas para telenovelas, com vistas a investir em um produto cultural de êxito garantido. 
Entre os motivos que elenca para explicar porque consente que seus romances sejam adaptados para a $\mathrm{TV}$, apesar de considerar que as adaptações de algum modo "deturpam" a obra original, Jorge Amado (1994, p.258) não se priva de declarar: "Sou um escritor que vive exclusivamente dos direitos autorais provenientes das edições, traduções e adaptações de meus livros, não tenho outra fonte de renda." $\mathrm{E}$, quando se dirige imaginariamente a algum romancista que porventura sinta-se angustiado ao ter a sua obra vertida para outra linguagem, aconselha: "se você não quer sofrer com a adaptação de seu romance, meu confrade, não assista ao filme, à novela, à peça, à desgraceira. Receba os direitos autorais adiantados, cobre alto, o mais alto que puder - é uma compensação" (AMADO, 1994, p. 258).

Esse reconhecimento do caráter fiduciário da arte evoca uma concepção que, denegada no contexto da alta modernidade estética, já se encontrava bem estabelecida entre poetas da Antiguidade Clássica, conforme fica explicitado no estudo de Jacyntho Lins Brandão (2002) sobre o estatuto da escrita poética nos primórdios da cultura ocidental. De acordo com o pesquisador, muito distante das conhecidas idealizações românticas acerca da criação literária como força guiada espontaneamente pelos caprichos da Musa, um poeta como Píndaro, por exemplo, veiculava em seus versos o entendimento de que "o poíema (aquilo que resulta do poieîn, do fazer, do compor) inclui também as marcas de um empólema (isto é, o que resulta da atividade de vender)" (BRANDÃO, 2002, p. 117). Em um contexto no qual a escrita principiava a exercer o seu importante papel de conservação e difusão, a antiga poesia grega era entendida, pelos seus contemporâneos, como um bem a ser propagado e usufruído em sua materialidade. E ela não cumpriria tal função se não fosse mercada, negociada de porto em porto, por toda a costa do Mediterrâneo.

Profissional da escrita, que desde muito cedo retirou do ofício com a literatura o seu sustento, Jorge Amado não se constrange ao mencionar os interesses pecuniários que estão em jogo nas vendas de seus direitos autorais para a televisão. Contudo, tendo em vista que o funcionamento de um mercado de bens simbólicos não se resume a transações de cunho estritamente comerciais, pode-se observar que o escritor também se mostra atento ao valor de uso cultural da teledramaturgia. E esse valor de uso vai se constituir no outro motivo que o leva a aceitar de bom grado as telenovelas derivadas de seus romances, por considerar a força de alcance da mídia televisiva junto a um público que, em geral, não transita pela cultura letrada:

(...) a obra escrita alcança um público de alguns milhares de leitores, a tiragem de dez mil exemplares já é considerável (...) Enquanto isso os filmes, as novelas e séries de televisão são vistos por milhões de espectadores, incluindo milhares e milhares de analfabetos sem possibilidade de acesso ao livro. Tieta - falo da novela de televisão escrita por Aguinaldo Silva baseada em meu romance - era vista cada noite por cinquenta milhões de apaixonados, segundo me informam (AMADO, 1994, p. 257).

No Brasil, como em grande parte da América Latina, a mídia eletrônica historicamente substitui o meio clássico de erudição, que é o texto escrito. E assim, conforme observa Jesús Martín-Barbero (2002), as maiorias nacionais latino-americanas se apropriam da modernidade através da gramática do rádio, do cinema e da televisão, isto é: sem passar pelo livro, sem abandonar a cultural oral. Sensível a essa questão, Jorge Amado não se furta à oportunidade de buscar o público lá onde este majoritariamente se encontra. E, neste caso, não é nas livrarias, nas feiras literárias e bienais, mas diante das telas da TV. Para além de um "negócio", os contratos do escritor com a cultura midiática representam, sem dúvida, a possibilidade de atingir leitores-receptores que estão substancialmente distanciados dos espaços mais legitimados do campo literário (SILVA, 2006).

É um fato incontestável que escritores de êxito no mercado editorial têm a sua produção requisitada para adaptações da teledramaturgia, o que faz da televisão um meio singular de disseminação e promoção da literatura no Brasil. E não seria diferente no caso de Paulo Coelho, haja vista que o seu romance Brida foi adaptado para uma telenovela de título homônimo, exibida em 1998 pela emissora Manchete, hoje extinta. ${ }^{1}$ Embora essa telenovela seja, até o momento, o único registro de exibição da sua obra em rede nacional, há relatos de outras propostas anunciadas mas não concretizadas, como a da Rede Globo, que cogitou a adaptação de $O$ diário de um mago para a feitura de uma minissérie nos 1990.

Comparando com as experiências de outros escritores, cujo exemplo mais notório é o do próprio Jorge Amado, a quase inexistência de produtos de teleficção gerados a partir da obra de Coelho no Brasil torna evidente que o seu êxito de público se firmou basicamente no espaço tipográfico do livro e no circuito do impresso. Essa singularidade foi valorizada por Heloísa Buarque de Hollanda, quando declarou, em uma entrevista: "Eu acho que a gente é um país de analfabetos, que não tem hábito de leitura, que não tem a cultura da leitura, então creio que se uma pessoa está lendo Paulo Coelho eu ajoelho e beijo

\footnotetext{
A telenovela Brida, redigida por Jayme Camargo e sob direção de Walter Avancini, teve o seu desempenho prejudicado em virtude dos problemas financeiros enfrentados pela emissora, que, ao declarar falência naquela época, comprometeu a execução de toda a sua programação já em andamento.
} 
os pés." E mais adiante, acrescenta: "Sem falar que ele alimenta e agiliza o mercado, abre livraria, vende papel" (apud TRAVANCAS, 2001, p. 138).

A autora saúda a contribuição de Coelho para o alargamento da prática da leitura no Brasil, uma proeza que, a princípio, pode ser creditada à iniciativa do escritor em simplificar ao máximo a estrutura de seus textos, produzindo uma literatura pautada na comunicabilidade,

fiel aos esquemas do gênero folhetinesco, de popularidade comprovada. Aqui, também não se deve perder de vista que o mercado de livros de fins dos anos 1980, momento em que Coelho alavanca a sua carreira no Brasil, apresenta condições de funcionamento muito superiores, comparando-se $a ̀$ primeira metade do século XX, na qual floresceu aquela tradição bacharelesca, referida por Paes (1990). Contudo, mais além dos recursos de linguagem e das condições propícias do mercado, é digno de nota o movimento realizado por Paulo Coelho no sentido de descentralizar o feitio institucionalizado do livro como bem material e simbólico de alta cotação. Se o códice impresso, como signo máximo de ilustração e erudição no interior da tradição cultural letrada, ocupa um lugar privilegiado frente a outras mídias, especialmente as massivas, como o rádio, a televisão e, mais contemporaneamente a internet, Coelho procura desmontar a hierarquia e fazer do livro um objeto desauratizado. Segundo o que ele próprio afirmou em uma de suas entrevistas:

editar livros sempre foi considerada uma arte de elite, de uma pequena igrejinha intelectual onde as pessoas se criticam, se comentam, mas ninguém chega ao que interessa, que é você sair na rua agora com um livro e o cara vir falar que já leu (COELHO, 1996, p. 31).

Nota-se aqui o entendimento da literatura como uma prática dessacralizada, destituída do viés elitista, do ponto de vista tanto da produção quanto da recepção, o que serve de traço norteador para a opção que o escritor assumiu em seu percurso profissional, a saber: conquistar o êxito editorial junto a grandes públicos. Para realizar tal feito, Coelho concebe que o livro deve circular em pé de igualdade com qualquer outro objeto no interior da cultura. E esse posicionamento é identificado pelo seu primeiro editor, Ernesto Mandarino, quando se reporta aos esforços do escritor para divulgar a sua produção ainda no início da carreira:

Paulo Coelho era divulgador da Polygram, ele usou no livro a mesma técnica que usava para divulgar fitas. Queria transformar o livro em produto de grande aceitação popular, via o livro como um produto vendável. Paulo Coelho fez um trabalho que os outros autores não fizeram. Ele se divulgava, fazia conferências, palestras, corria livrarias, imprensa, fazia um trabalho excepcional(apud ROMANCINI, 2002, p. 97).

O autor "vende" a sua força de trabalho ao lado de sua obra e conjuga, assim, o papel do escritor com o do promotor cultural. Tendo reunido em seu currículo a passagem pelo jornalismo, pela autoria de músicas pop e a produção executiva na indústria fonográfica, Paulo Coelho dá mostras do seu traquejo profissional quando se lança à iniciativa de importar expedientes publicitários do mercado da música popular para o universo da literatura, tradicionalmente mais elitizado. Essa interpenetração de campos culturais distintos, deflagrada quando o escritor equipara "livros" e "fitas" ou quando patrocina propagandas de rádio para os seus livros, conforme relatado em sua biografia por Fernando Morais (2008), presta conta das transformações contemporâneas quanto aos procedimentos de consagração artística. Transformações que colocam em abalo a pretensão moderna de se criar uma esfera autônoma para a literatura face às leis do mercado, como apontado por Nestor Canclini (2003).

Foi a expertise de promotor cultural que levou Paulo Coelho, já no início da carreira, a se interessar pelos aspectos executivos da produção editorial, buscando se inteirar do valor final dos livros e orientando cortes de orçamento que os reduzissem a preços mais acessíveis (MORAIS, 2008). E com vistas a expandir a circulação de sua obra, ele publicou e assinou textos em formatos diversificados, como audiobooks e quadrinhos, e apostou firme nas edições de bolso, as quais podiam ser adquiridas tanto em bancas de jornais quanto em stands de supermercados, formando uma rede de distribuição flutuante e difusa, durante os anos 1990. Em tempos mais recentes, após o advento das mídias digitais, não é surpreendente, portanto, que todos os seus livros se encontrem disponíveis gratuitamente para a leitura nas telas de computadores, tablets ou smartphones.

No decorrer de uma trajetória que conta hoje mais de três décadas, Paulo Coelho sem dúvida agilizou o comércio livreiro, conforme observado anteriormente por Heloísa Buarque de Hollanda. Mas tal feito decorre de articulações que ultrapassam as convenções desse comércio, ao menos nos moldes legados por uma cultura erudita. A esse propósito, é válido destacar que a sua produção literária também esteve incluída no cardápio da revista de cosméticos Avon, bem como de outros catálogos similares. De 1990 até, pelo menos, o final da década de 2000 , os seus romances circularam "de porta em porta", através do contato direto e pessoal que se constrói entre vendedores e clientes, conforme a prática corrente na comercialização dos produtos ofertados nessas revistas. Por compreender um canal de distribuição distanciado do espaço oficial das livrarias, dos lançamentos e saraus 
de autógrafos, tal modo de aquisição e apropriação dos livros por certo desvia dos rituais mais ortodoxos da cultura literária, ao tempo em que atende uma parcela de leitores presumivelmente pouco ambientados com os códigos dessa cultura (OLIVEIRA, 2015).

Alguns analistas vão creditar o sucesso de Paulo Coelho ao chamado boom da literatura esotérica nos anos 1980-90, considerando que ele se tornou o único representante desse gênero no Brasil. Aliado a isso, darão relevo à linguagem acessível de suas narrativas, requisito fundamental para consagrar um best seller no mercado editorial. Quanto à Jorge Amado, os críticos podem dizer que o seu êxito se deve, em grande parte, à iniciativa de expressar a cultura nacional, de retratar e/ou criar mitos de baianidade/brasilidade (GOLDSTEIN, 2003) através de suas personagens envolventes. E aqui também se soma a construção de narrativas fluidas, recheadas com altas doses de oralidade, criadas por um habilidoso "contador de histórias" - expressão com a qual ele próprio costumava orgulhosamente se definir.

Reconhecendo a pertinência dos aspectos acima mencionados, é possível acrescentar que o imenso sucesso alcançado e sustentado pelos dois escritores decorre do modo pelo qual eles ultrapassaram a dimensão da literatura, do "específico" literário, para se inscreverem no plano expandido da cultura, onde souberam negociar de forma competente com recursos e capitais simbólicos de diversas procedências. Nesse movimento de expansão, foi sobretudo o entrelaçamento do literário com o mercadológico e o midiático que se fez a condição fundamental para assegurar tanto a Jorge Amado quando a Paulo Coelho uma aproximação continuada com os públicos que eles vieram formando em suas trajetórias.

E assim, entre outros exemplos igualmente vultosos, não é por acaso que a narrativa de Dona Flor e seus Dois maridos, que teve os seus 50 anos de existência comemorados recentemente, em 2016, tornou-se campeã de bilheteria nas salas de cinema do Brasil durante três décadas, através de sua adaptação para o filme homônimo de Bruno Barreto - um feito excepcional para o cinema nacional. Como também não é à toa que o alentado $O$ Alquimista entrou para o Livro dos recordes Guinnes, em 2003, como um dos livros mais traduzidos do mundo, sendo que o seu autor foi eleito o único escritor que autografou a maior contagem de traduções de sua obra em um único dia. E tudo isso para o desagrado daquela parcela da crítica que não se conforma com o fato de que a rubrica literatura esteja associada a expressões como "recorde" ou "bilheteria", as quais implicam em largas tiragens, vastos públicos, grandes negócios e fazem emergir o viés da quantidade onde deveria imperar apenas o critério da qualidade estética, esta última tida como sinônimo de restrição, escassez e não-vulgarização. Como observa Bourdieu (2004), a oposição entre "qualidade" e quantidade", que está nas bases dos julgamentos de valor em matéria de arte, fundamenta-se, de forma correlacionada, na distinção propriamente social entre os produtos das elites e os produtos das massas.

Em diversas matérias de jornais e revistas, costuma-se aproximar os nomes de Jorge Amado e de Paulo para registrar os milhões de livros que ambos têm distribuídos, tanto no Brasil quanto no exterior. Diz-se, principalmente, que são os autores brasileiros mais conhecidos no mundo e que o sucesso de um só se compara ao do outro. A aproximação não vai além deste ponto, como se desses dados estatísticos nada mais se pudesse extrair. Contudo, se os dois escritores fossem indagados acerca do significado do êxito comercial que os une, eles possivelmente responderiam que tais índices possuem um mérito singular, o qual não se resume à coroação de um trabalho que teria como meta tão somente o prestígio e notoriedade no campo profissional, a despeito das negativas da crítica ou até mesmo em função delas.

Nos itinerários por eles percorridos, o valor da "quantidade" se descortina quando é levada em conta a personagem por trás das cifras que o mercado celebra e que a instituição literária, em sua versão ortodoxa, por vezes tem desprezado. É a essa personagem que Coelho se dirige quando lança o seguinte comentário, numa entrevista concedida em 1996: "O que me toca mais é o anônimo, é o vendedor da barraca que fica em frente ao posto três, que comenta o meu livro. $\mathrm{O}$ cara que vende frutas" (COELHO, 1996:31). E é a essa personagem que Amado dá voz, ao representá-la poeticamente em seu livro de memórias:

Onde quer que eu chegue, nas comarcas do mundo, províncias e Metrópoles, vilarejos, encontro mesa posta e escuto uma palavra amiga. Alguém me diz: li teu livro, companheiro, ri e chorei, me comovi. (...) És escritor porque eu existo, teu leitor (...) (Amado, 1994, p. 375-376).

O leitor - aquele que se vai encontrar em todo e qualquer lugar. Eis a razão suficiente para justificar e dar por encerradas, ao menos por ora, as linhas deste diálogo.

\section{Referências}

AMADO, Jorge. Amado defende Paulo Coelho na França. Folha de São Paulo, São Paulo, Caderno Ilustrada, 18 maio 1995. Entrevista concedida a André Fontenelle. Disponível em: <http://www1.folha.uol.com.br/fsp/1995/5/18/ilustrada/20. html>. Acesso em: 22 abr. 2017.

AMADO, Jorge. Navegação de cabotagem; apontamentos para um livro de memórias que jamais escreverei. Rio de Janeiro: Record, 1994. 
AMADO, Jorge. Por que se comemora a caduquice? Jornal do Brasil, Rio de Janeiro, 04 ago. 1992, p. 2. Entrevista concedida a Cintia Medeiros.

BOURDIEU, Pierre. As regras da arte: gênese e estrutura do campo literário. Tradução Maria Lucia Machado. São Paulo: Companhia das Letras, 1996.

BOURDIEU, Pierre. A Produção da crença: contribuição para uma economia dos bens simbólicos. Tradução Maria da Graça Jacintho Setton. São Paulo: Zouk, 2004.

BRANDÃO, Jacyntho Lins. Poesia grega e mercadoria fenícia. In: MARQUES, Reinaldo; VILELA, Lucia Helena (Orgs.). Valores: arte, mercado, política. Belo Horizonte: UFMG/ Abralic, 2002. p. 117-134.

CANCLINI. Nestor Garcia. Culturas Hibridas: estratégias para entrar e sair da modernidade. Tradução Heloísa P. Cintrão e Ana Regina Lessa. São Paulo: EDUSP, 2003.

COELHO, Paulo. Diário do Nordeste, 09 ago. 2015. Ao maior de todos. Disponível em: $<$ http://diariodonordeste.verdesmares. com.br/cadernos/caderno-3/coluna/paulo-coelho-1.138/paulocoelho-1.1357991>. Acesso em: 13 abr. 2017.

COELHO, Paulo. Guerreiro das letras. Continente multicultural, Pernambuco, n. 15, mar. 2002. Entrevista concedida a Luciano Trigo.

COELHO, Paulo. Entrevista com Paulo Coelho. Imprensa, São Paulo, n. 7, set. 1996. Entrevista concedida a Ari Schneider.

DUARTE, Eduardo Assis. Jorge Amado e o bildungsroman proletário. Revista Brasileira de Literatura Comparada, v. 2, p. 157-64, maio 1994.

GOLDSTEIN, Ilana Seltzer. O Brasil Best-Seller de Jorge Amado: literatura e identidade nacional. São Paulo: Editora Senac, 2003.

MARTÍN-BARBERO, Jesús. América Latina e os anos recentes: o estudo da recepção em comunicação social. In: SOUSA, Mauro Wilton de (Org.). Sujeito, o lado oculto do receptor. Tradução Silvia Cristina Dotta e Kiel Pimenta. São Paulo: Brasiliense, 2002. p. 39-68.

MICELI, Sergio. Intelectuais à brasileira. São Paulo: Companhia das Letras, 2001.

MORAIS, Fernando. O mago. São Paulo: Planeta, 2008.

OLIVEIRA, Sayonara Amaral de. Aos cuidados de Paulo Coelho.com: um estudo de recepção nos blogs do escritor. Salvador: Edufba, 2015.

ORTIZ, Renato. A moderna tradição brasileira: cultura brasileira e indústria cultural. São Paulo: Brasiliense, 2001.

PAES, José Paulo. Por uma literatura brasileira de entretenimento (ou: o mordomo não é o único culpado). A aventura literária: ensaios sobre ficção e ficções. São Paulo: Companhia das Letras, 1990. p. 25-38.

ROMANCINI, Richard. Apropriações de Paulo Coelho por usuários de uma biblioteca pública: leitura popular, leitura popularizada. 2002. 179 f. Dissertação (Mestrado em Ciências da Comunicação) - Escola de Comunicações e Artes, Universidade de São Paulo. Dissertação defendida em 2002.

SILVA, Márcia Rios da. O rumor das cartas: um estudo da recepção de Jorge Amado. Salvador: Fundação Gregório de Matos/Edufba, 2006.

TRAVANCAS, Isabel. O livro no jornal: os suplementos literários dos jornais franceses e brasileiros nos anos 90. São Paulo: Ateliê Editorial, 2001.

Autora:

SAYONARA AmARAL DE OLIVEIRA Universidade do Estado da Bahia. Salvador, BA, Brasil. sayo22@terra.com.br

Recebido: 30/04/2017 Aprovado: $28 / 07 / 2017$ 